\title{
Update on Women in Physics in Finland
}

\section{Miikkulainen, Kukka}

AIP Publishing LLC

2019

Miikkulainen , K , Ott , J \& Vapaavuori , J 2019 , Update on Women in Physics in Finland . in G Cochran , C Singh \& N Wilkin (eds), Women in physics . , 050015 , AIP Conference Proceedings, vol. 2109 , AIP Publishing LLC , Melville, NY, IUPAP International Conference on Women in Physics , Birmingham , United Kingdom , 16/07/2017 . https://doi.org/10.1063/1.5110089

http://hdl.handle.net/10138/312226

https://doi.org/10.1063/1.5110089

publishedVersion

Downloaded from Helda, University of Helsinki institutional repository.

This is an electronic reprint of the original article.

This reprint may differ from the original in pagination and typographic detail.

Please cite the original version. 


\section{Update on women in physics in Finland}

Cite as: AIP Conference Proceedings 2109, 050015 (2019); https://doi.org/10.1063/1.5110089 Published Online: 03 June 2019

Kukka Miikkulainen, Jennifer Ott, and Jaana Vapaavuori

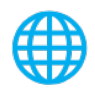

\section{ARTICLES YOU MAY BE INTERESTED IN}

France: Charter for gender fairness at conferences

AIP Conference Proceedings 2109, 050016 (2019); https://doi.org/10.1063/1.5110090

Areas of action: Equal opportunities for women and men in physics in Germany

AIP Conference Proceedings 2109, 050017 (2019); https://doi.org/10.1063/1.5110091

How successful are women in physics in Ireland?

AIP Conference Proceedings 2109, 050021 (2019); https://doi.org/10.1063/1.5110095

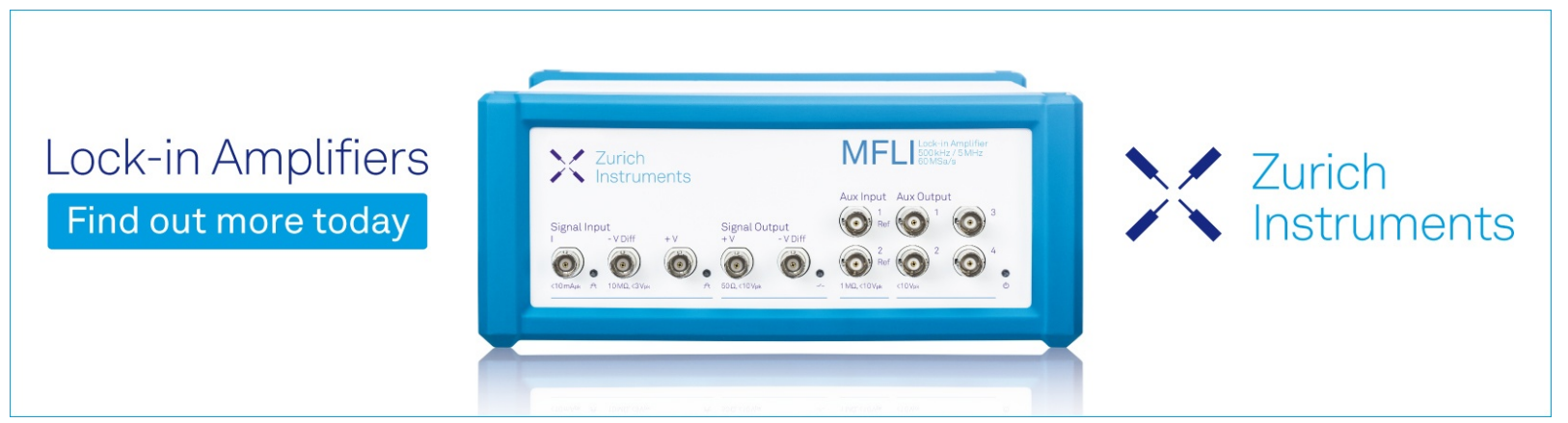




\title{
Update on Women in Physics in Finland
}

\author{
Kukka Miikkulainen $^{1, \text { a) }}$, Jennifer Ott ${ }^{2, \text { b) }}$, and Jaana Vapaavuori ${ }^{3, c)}$ \\ ${ }^{1}$ Oxford Instruments Technologies Oy, Tekniikantie 12, FI-02150 Espoo, Finland \\ ${ }^{2}$ Helsinki Institute of Physics, P.O. Box 64 (Gustaf Hällströmin katu 2), \\ FI-00014 University of Helsinki, Finland \\ ${ }^{3}$ Tampere University of Technology, Laboratory of Chemistry and Bioengineering, P.O. Box 541, FI-33101 \\ Tampere, Finland \\ ${ }^{a)}$ Corresponding author: kukka.miikkulainen@oxinst.com \\ b)jennifer.ott@helsinki.fi \\ c)jaana.vapaavuori@gmail.com
}

\begin{abstract}
There has not been much change in the status of women in physics in Finland during the last three years. Numbers and problems remain the same. Some interesting events have been held, and excellent websites and initiatives have been started. Finland would benefit from nationwide gathering of statistical data on the numbers and salaries of female students and staff at academic institutions and on women working in STEM fields in industry to better quantify the problems. Lack of coordination and resources make it difficult to have long-term programs and to follow the outcomes of the initiatives started.
\end{abstract}

\section{NUMBERS}

The statistics for women in physics at the undergraduate and graduate student stage have not changed much in recent years. In the 2000 s the percentage of women at the $\mathrm{PhD}$ level has been $20 \%$ to $30 \%$, whereas in some physics departments almost half of new students are women. Quite a significant number of them do not graduate, however, but instead are there to prep for entry into medical school or go on to study something else. As a result, only around $25 \%$ of physics graduates are women. The number of women professors in physics is currently 10 , which is only $7 \%$ of all physics professors in Finland [1]. The corresponding figure averaged over all fields is 21\% [1], while 53\% of all PhD graduates are women [2]. Of the members of the Finnish Physical Society, 17\% are female [1].

\section{LATEST EVENTS AND INITIATIVES}

The Women in Science network launched at the Kumpula Science Campus of the University of Helsinki in 2014 has been quite active, holding workshops and maintaining a very informative website, which also includes inspirational biographies and interviews of women scientists. In addition, the IT Centre for Science has launched a website called the Perfect Equation (Woman + Computational Science) [3], which introduces the work and careers of women scientists who use computational methods, including several physicists. Lunch meetings have also been resuscitated in Kumpula and are now held regularly.

Another seminar on diversity in mathematics and physics was held at Aalto University in autumn 2014, and the Helsinki Association of Women Researchers has organized seminars on gender equality issues and more informal meetings for women researchers. Many physicists have participated in these events.

Technology Industries of Finland has held a successful series of Women in Tech brunches. These brunches target women in all STEM fields working in industry, offering interesting lectures and opportunities for networking. They have been frequently sold out and will be continued. In addition, a new innovation prize for women has been set up. 
Many universities have outreach programs to attract young people into STEM subjects. The problem with these, as with the gender equality issues, has been that the efforts are rather scattered around the country, with no clear coordination or exchange of ideas among institutes. The LUMA Centre Finland [4] searches for solutions to these problems through promoting teacher education, sponsoring online science clubs, and holding events around the country, such as day summer camps for primary and secondary school students and science day events for younger children and families. It is a joint effort of several universities.

One problem with the physics outreach programs in particular is that many are aimed at high school students who are already into science and mathematics and have perhaps already chosen their preferred field of interest. For the girls this is usually medicine, or chemistry, which raises questions of whether teachers and parents have some unconscious bias, making these the only alternatives mathematically gifted girls even consider.

In recent years there has been no outreach activities targeted to girls specifically. It seems that their underrepresentation is not even perceived to be a problem.

\section{PERSISTING PROBLEMS}

The problems encountered by women physicists in Finland remain unchanged and unchallenged. Despite being a forerunner in gender equality in many areas, Finland has a very gender-segregated workplace. Salaries tend to be low in many of the "women's fields," and many women take off long periods from work for family reasons. Career advancement tends to be slower, and women do not reach top positions in either industry or academia. There are also persistent problems of belittling and sexual harassment, which are sometimes made more difficult by the small number and low visibility of female role models. These issues are very well described by J. Vainio in [5], a study based on extensive interview material of female and male physicists working in academia and in industry, which in its introductory chapters also gives a concise overview of the history of physics, and women in physics, in Finland.

There is no nationwide gathering of statistics on women in physics, or anyone coordinating their collection. All events and initiatives are started and often also run by energetic individuals with little or no allocated resources or support. Given the lack of resources or more long-term funding, these efforts tend to wither away after the initial enthusiasm has worn off, as individuals do not have the time or energy for continued work in this field in addition to all their other duties.

\section{PARENTAL LEAVES BACKFIRING}

In Finland it is possible to take very long parental leaves (up to three years), which are currently very unevenly distributed between men and women. There has been a lot of public discussion lately on how to improve the situation, and there are now plans to make the leaves shorter, and some of them have already been allocated to fathers only. Resistance is hard, as it has taken years to gain the right to take these leaves. Research evidence is flung back and forth on how harmful or beneficial it is for children under the age of three to be cared for by someone other than their parents while parents are at work, and women are made to feel bad about their choices, whatever they are. On the other hand, women with no family are also reporting discrimination due to family status, as often the only valid reason for taking time off or working shorter hours is taking care of children or elderly relatives.

The fact that in Finland people normally graduate quite late aggravates these problems, as the long family leaves tend to coincide with the years that would be very important for advancing one's career. Especially for an academic career, the requirement to do a post-doc abroad would be much easier to fulfill if people got their PhDs in their 20s rather than 30 s.

\section{ACKNOWLEDGMENTS}

We would like to thank Dr. Eija Tuominen and Professor Hanna Vehkamäki for their help with collecting the data, all the participants of the Women in Physics session at the Annual Meeting of the Finnish Physical Society for their input, and the Finnish Physical Society for the funding to attend the conference.

\section{REFERENCES}

1. E. Tuominen and H. Vehkamäki (private communication). 
2. Statistics Finland, "Yliopistojen opiskelijat ja tutkinnon suorittaneet koulutusasteen, -alan (opetushallinnon 1995 luokitus) ja sukupuolen mukaan 2015," http://tilastokeskus.fi/til/yop/2015/yop_2015_2016-05-10_tau_001_fi.html.

3. CSC-IT Centre for Science, "Woman + Computational Science = Perfect Equation," Women in Computational Science, https://www.csc.fi/web/taydellinenyhtalo/.

4. LUMA Centre Finland, "LUMA Centre Finland," http://www.luma.fi/en/.

5. J. Vainio, "Hegemony, contradiction, and gender in the context of Finnish university physics," PhD thesis, University of Helsinki, 2012. 